\title{
Implementasi Plex Media Server dan Adguard Home pada Raspberry pi sebagai Home Server
}

\author{
Rudi Hermawan ${ }^{1}$, Siti Maesaroh ${ }^{2}$, Dewanto Rosian Adhy ${ }^{3}$, Jujun Juharsa $^{4}$, Ari Patriana ${ }^{5}$ \\ ${ }^{12345}$ Sekolah Tinggi Teknologi Ybs Internasional, Komplek Mayasari Plaza, Jl. Pasar Wetan, Argasari Kecamatan Cihdeung, Tasikmalaya 46122, \\ Indonesia \\ ${ }^{1}$ rudihermawan567@gmail.com 2sitimaesaroh40@gmail.com,33ewanto_ra@sttybsi.ac.id, ${ }^{3}$ joensatriani.cool@gmail.com, \\ ari.patriana@sttybsi.ac.id
}

\section{INFORMASI ARTIKEL}

Sejarah Artikel:

Diterima Redaksi: 13-12-2021

Revisi Akhir: 30-12-2021

Diterbitkan Online: 31-12-2021

\section{KATA KUNCI}

\begin{tabular}{l}
\hline Raspberry Pi, \\
Adguard Home, \\
Plex Media Server, \\
Home Server, \\
Family protection. \\
KORESPONDENSI \\
\hline
\end{tabular}

Telepon: 081312261335

E-mail: rudihermawan567@gmail.com

\begin{abstract}
The computer revolution to this day continues to occur, current progress makes many variations of computer technology, especially those used for servers, Raspberry pi is a mini computer designed for minimalist servers. On the other hand, the high and fast flow of technology raises new problems, one of which is the issue of data security through threats embedded in advertisements and ageappropriate content filtering. This research was conducted using a Raspberry pi with Plex media server service and configuring a DNS Server to filter content with the Adguard Home application as Family protection. With the developments and problems above, it can be taken from the reliability of the Raspberry pi as a home server that was built and became a solution, with the service features of the plex media server and adguard home. Both server services can be used as a home server and family protection to maintain the security of data inserted through advertisements and content filtering, especially content in the form of video or sound.
\end{abstract}

\section{Pendahuluan}

Arus informasi dan kebebasan akses internet memiliki sisi positif dan negatif. Komunikasi bisa dilakukan dengan cepat, dapat menggunakan berbagai media dan informasi lebih cepat tersampaikan. Pengaruh negatif internet, khususnya untuk keluarga terutama orang tua dan anak yang minim literasi digital berpotensi jadi sasaran kejahatan internet [1]. Selain itu efek penggunaan media yang digunakan untuk mengakses internet seperti gadget, merupakan permasalahan tersendiri untuk pekembangan anak dalam keluarga [2].

Pembatasan akses terhadap konten sebenarnya sudah dilakukan oleh pemerintah, aplikasi yang dirancang untuk pembatasan internet bagai anak dalam keluarga juga sudah tersedia. Ketika terkoneksi ke internet meskipun sudah $47-53$ diproteksi dengan pembatasan akses dan aplikasi tetapi biasanya media lain bisa menjadi salah satu penyebab masuknya kejahatan atau dampak negatif sehingga diperlukan internet sehat atau pembatasan akses secara mandiri [3]. Family protection dapat dijadikan sebagai sebuah upaya untuk menangani masalah tersebut. Dibutuhkan home server pribadi yang digunakan untuk akses internet seluruh anggota keluarga. Dalam home server pengguna dapat lebih leluasa untuk membatasi akses informasi, media dan konten lainnya di internet [4], [5].

Dalam pembangunan home server dibutuhkan biaya yang besar jika dilakukan menggunakan spesifikasi komputer server yang biasa digunakan. Tetapi jika dilihat dari sisi kebutuhan dan penanganan terhadap beberapa permasalahan mengenai family 
protection, khususnya untuk akses konten internet, tidak memerlukan spesifikasi server yang terlalu tinggi. Raspberry $\mathrm{Pi}$ sudah banyak digunakan sebagai mini komputer atau mini server dengan beberapa kelebihan dan kekurangannya. Raspberry PI merupakan sebuah mini komputer yang memiliki kemampuan untuk dipasang perangkat lunak yang dapat dikonfigurasi dan dimodifikasi sesuai dengan yang diinginkan [6] . Raspberry pi sering digunakan untuk keperluan teknologi Internet of Things (IoT) seperti: Home Automation, Smart Home sampai digunakan sebagai komputer server untuk pengontrolan lampu jalan dari jarak jauh [7], [8]. Raspberry pi juga dapat digunakan sebagai Web Server dengan arsitektur yang sederhana, tetapi cukup untuk memenuhi kebutuhan Server sesuai dengan spesifikasi yang diinginkan pengguna [9].

Layanan Raspberry pi semakin berkembang diikuti aplikasi atau software yang kompatibel dengan perangkat Mini Personal Computer (PC). Seperti contoh, software Adguard Home, AdGuard Home adalah perangkat lunak seluruh jaringan untuk memblokir iklan \& pelacakan akses terhadap semua pengguna jaringan. Setelah digunakan, user bisa mengatur sesuai dengan kebutuhan dan hanya dengan satu kali konfigurasi maka akan mencakup atau diterapkan kepada setiap perangkat rumah yang terhubung ke server. User tidak memerlukan perangkat lunak sisi klien untuk itu. Dengan Teknologi Internet Of Things (IoT) maka perangkat yang terhubung dapat dikontrol oleh software Agduard sepenuhnya .

Perkembangan terbaru dari Raspberry pi, salah satunya dukungan terhadap layanan server media. Plex Media Server merupakan salah satu layanan server media yang didukung oleh Raspberry pi. Plex Media Server adalah suatu media server yang digunakan untuk mendistribusikan konten multimedia kepada klien (gerakan open source wordpress). Plex memiliki keunggulan transcoding yang menjamin setiap konten multimedia bisa diputar menggunakan perangkat apapun.

Berdasarkan permasalahan yang telah dipaparkan, acuan dari penelitian sebelumnya dan metode terkait yang sudah ada, maka home server menggunakan Raspberry pi dengan layanan Plex media server dan software Adguardhome dapat dijadikan sebuah rekomendasi baru untuk pembangunan home server yang ramah anak atau ramah keluarga dan dapat digunakan untuk mengatasi masalah kejahatan internet.

\section{Ulasan Penelitian Terkait}

Penelitian terkait home server dan penelitian yang relevan sebelumnya mengenai penelitian yang diangkat salah satunya adalah mengenai [10] penggunaan flex media server pada jaringan Local Area Network (LAN), dalam penelitian ini dibahas mengenai pemasangan Plex Media Server menggunakan Windows 7, Dalam perancangan sistem media server ini menggunakan software plex sebagai media server nya, dan objek yang digunakan dalam penelitiannya pada perangkat komputer menggunakan router TPLINK MR3420 untuk membagikan file-file multimedia ke jaringan melalui media wireless. Hasil dari Implementasinya adalah server dapat di akses melalui wireles dan perlu dilakukan pengembangan infrasturktur yang lebih baik dari segi desain maupun kualitas untuk meningkatkan kualitas streaming di masa mendatang.

Penelitian Terkait lainnya adalah mengenai pengunaan Raspberry pi dengan hadop dengan tujuan melakukan pembatasan penyimpanan [11]. Penelitian ini mencoba melakukan pembatasan kuota menggunakan disk quota pada directoy user dapat dilakukan dengan menggunakan Hadoop. Penelitian ini merancang teknologi storage server dengan menggunakan perangkat lunak Apache Hadoop Distributed File System (HDFS) dan Java Development Kit (JDK) yang diimplementasikan pada komputer Raspberry $\mathrm{Pi}$ sebagai komputer server, dengan menggunakan pembatasan kuota kapasitas penyimpanan. Rancangan storage server sebagai penyimpanan cadangan ini dapat digunakan bersamasama namun dengan pembatan jumlah kapasitas dan directory. Pembatasan kuota kapasitas yang diberikan sebesar 10GB untuk masing-masing directory user.

Penelitian ketiga adalah mengenai Raspberry pi yang digunakan untuk memfilter konten menggunakan layanan dari software Content Filtering [12], dalam penelitian ini dibahas mengenai pihole sebagai adblocker pada Raspberry PI. Pi-hole adalah adblocker yang biasa digunakan menggunakan jaringan Linux dan aplikasi pemblokiran pelacak Internet yang bertindak sebagai lubang pembuangan Domain Name System (DNS) dan secara opsional server Dynamic Host Configuration Protocol (DHCP), yang dimaksudkan untuk digunakan pada jaringan pribadi. Pihole ini dirancang untuk digunakan pada perangkat tertanam dengan kemampuan jaringan, seperti Raspberry Pi, tetapi dapat digunakan pada mesin lain yang menjalankan Linux dan implementasi cloud.

\section{Metodologi}

\subsection{Persiapan Topologi / Arsitektur Jaringan}

Dalam Implementasi pada penelitian ini digunakan 1 Raspberry pi sebagai server, Access point sebagai Hospot Setup dan Komputer serta Smartphone sebagai user yang mengakses server Raspberry Pi.

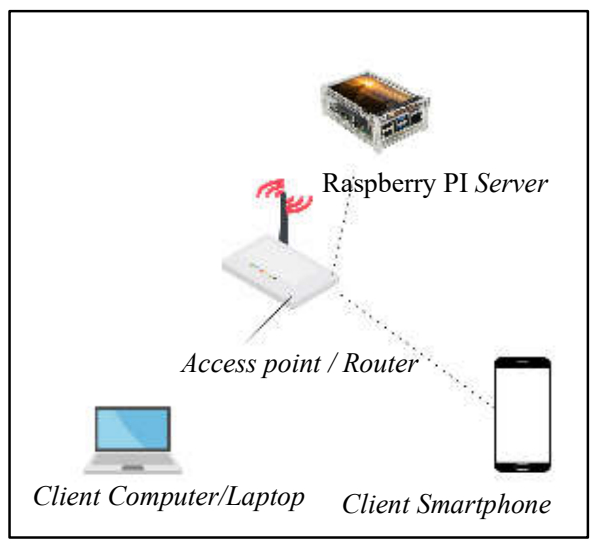

Gambar 1. Arsitektur Jaringan 
Pada topologi yang dikembangkan seperti pada gambar 1, server diinstall dan dipasang layanan server media menggunakan Plex dan AdguardHome sebagai aplikasi untuk monitoring penguna jaringan serta blokir iklan yang membahayakan.

\subsection{Installasi AdGuardHome}

Dalam penelitian ini, dilakukan pemasangan sistem operasi Raspberry Pi dan pemasangan jaringan, sehingga server sudah siap untuk dipasang adguard home untuk monitoring pengguna jaringan yang melewati server dan memblok iklan - iklan yang dianggap berbahaya dari website atau situs yang diakses oleh pengguna.

Pemasangan dimulai dari Upgrade dan Update sistem Raspberry pi yang dilakukan dengan perintah : apt-get upadte | apt-get upgrade. Selanjutnya lakukan pengunduhan untuk Adguardhome, gunakan perintah: wget https://static.adguard.com/adguardhome/release/AdGuardHome_li nux_arm.tar.gz seperti ditampilkan pada gambar 2 .

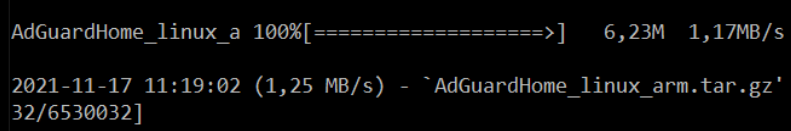

Gambar 2. Penguduhan Adguardhome

Tahap berikutnya ekstraksi file hasil unduh dan lakukan proses pemasangan software menggunakan perintah sudo cd /AgduardHomel/IAdGuardHome -s install seperti ditampilkan pada gambar 3 .

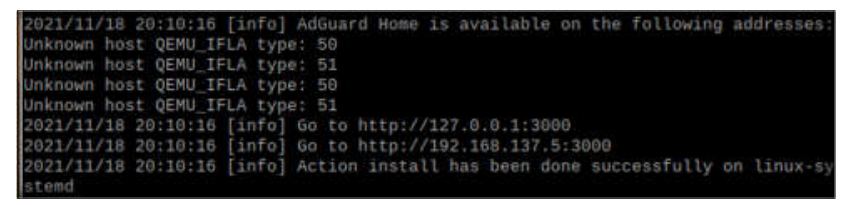

Gambar 3. Pemasangan AdGuardHome

Setelah diinstall sistem akan menampilkan ip address dan nomor port server yang dapat diakses untuk mengatur software AdguardHome. Pada penelitian ini server menggunaakn IP Address 192.168.137.5:3000. Pengaturan port ditampilkan pada gambar 4.

\begin{tabular}{|l|l|}
\hline & $(V)$ ADGUARD \\
\hline Adome & \\
\hline $\begin{array}{l}\text { Admin Web Interface } \\
\text { Listen interface }\end{array}$ & \\
\hline All interfaces & Port \\
\hline
\end{tabular}

Gambar 4. Pengaturan Port AdguardHome

Pengturan user dan password untuk kredinsial keamanan server khususnya untuk masuk kedalam software Adguardnya.

User dapat mengakses server melalui IP Address dan Port yang sudah ditentukan, dan login untuk masuk kedalam sistem AdGuardhome seperti ditampilkan pada gambar 5 .

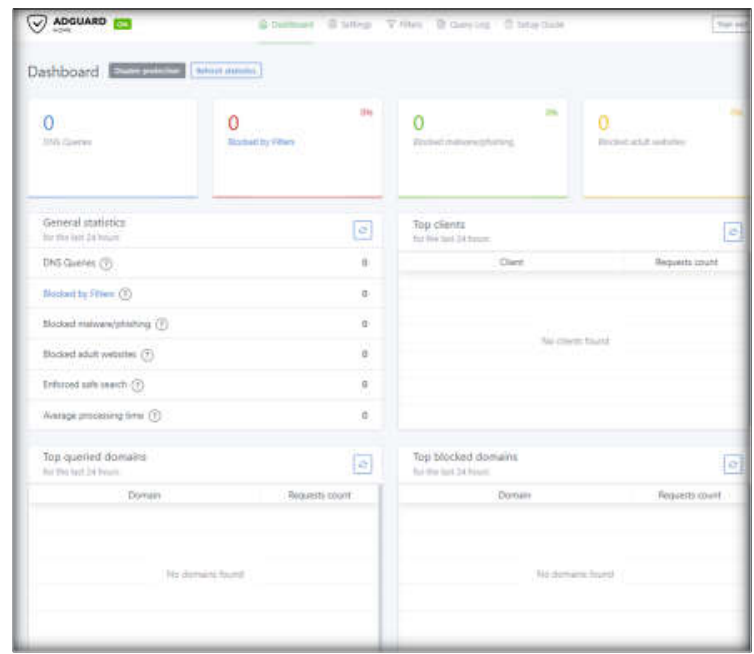

Gambar 5. Tampilan Dashboard AdguardHome

\subsection{Installasi Plex Media Server}

Dalam Media server, terdapat berbagai software modul yang menawarkan fitur dan mendukung atau compatible dengan Raspberry PI. Pada penelitian ini digunakan plex media server, karena memiliki paket untuk ujicoba yang cukup mumpuni dan bisa digunakan untuk home server. Instalasi Plex media server diawali dengan mengaktifkan package manager, download dari vendor secara langsung, package yang digunakan akan mentransfer file dan data melalui https. Untuk mengaktifkan package digunakan perintah sudo apt install apt-transport-https cacertificates curl. Selanjutnya aktifkan kunci GPG (GNU Privacy Guard) agar Plex media bisa dipasang direpositori Raspberry pi melalui perintah sebagai berikut:

- $\quad$ curl https://downloads.plex.tv/plex-keys/PlexSign.key sudo apt-key add

- $\quad$ echo deb https://downloads.plex.tv/repo/deb public main sudo tee letc/apt/sources.list.d/plexmediaserver.list

Setelah repositori Plex diaktifkan, selanjutnya lakukan installasi paket plex media server hasil unduhan sebelumnya, gunakan perintah : sudo apt-get install plex media server. Secara otomatis server akan menginstall paket plex media server dan pengguna hanya perlu memastikan bahwa internet yang digunakan stabil agar proses installasi tidak terganggu.

Setelah dilakukan pemasangan, selanjutnya memastikan paket hasil installasi berhasil dipasang dengan meggunakan perintah sudo systemctl start plexmediaserver | sudo systemctl status plexmediaserver. Jika pemasangan berhasil maka akan tampil seperti gambar 6. 


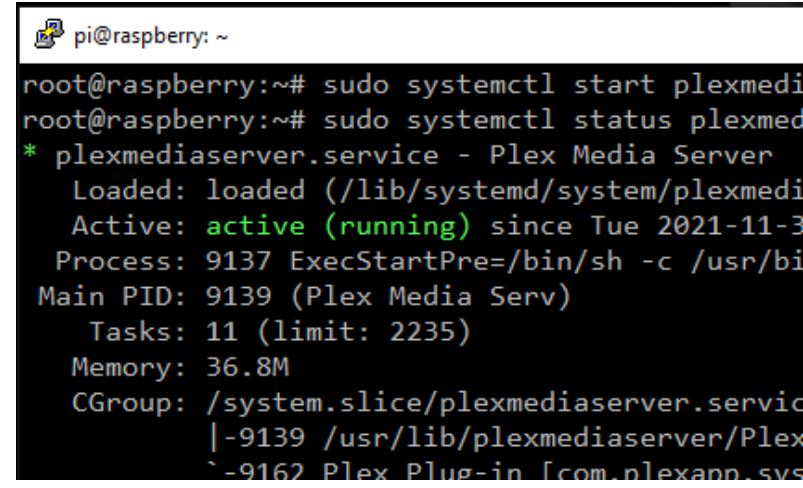

Gambar 6 . Verifikasi Pemasangan Plexmedia

Pada gambar 6 ditampilkan status "active (running)" yanag berarti plex media server sudah dapat digunakan.

\subsection{Pengaturan Access Point}

Konfigurasi acces point dilakukan secara standar hanya menambahkan IP Address Domain Name System (DNS) menggunakan ip dari server Raspberry pi yang digunakan.

\section{HASIL DAN PEMBAHASAN}

\subsection{Pengujian AdGuardhome}

Setelah dilakukan konfigurasi sebelumnya, pengujian Adguardhome bisa dilakukan dengan cara mengakses situs dari sisi client atau dari server. Pada pengujian ini dilakukan dari sisi client menggunakan komputer yang terhubung ke server.

Hal yang harus dipastikan adalah computer client harus dipastikan terhubung dengan server. Dalam penelitian ini computer client sudah terhubung dengan server dan dilakukan pengujian dengan mengakses situs situs tertentu.

Sebelum dilakukan pengujian, diberikan beberapa rule untuk AdguardHome, home server yang diimplementasikan. Salah satunya digunakan fitur block youtube pada pengaturan adguardHome.

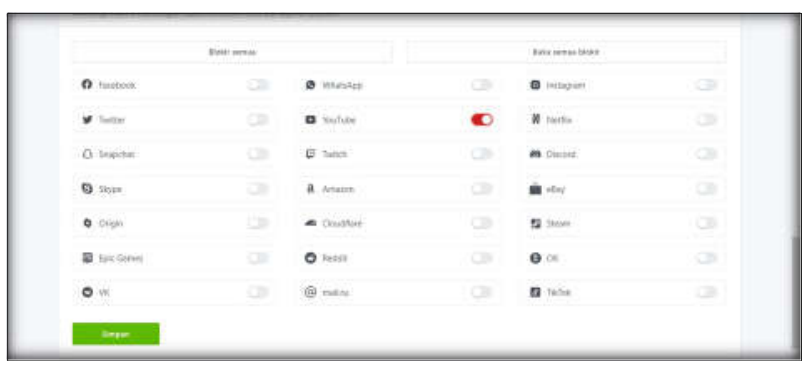

Gambar 8. Pengaturan Blok Situs

Dalam pengaturan Adguardhome ini ada beberapa situs yang bisa dibatasi penggunaannya, hal ini dapat digunakan untuk filter situs yang bisa diakses oleh setiap anggota keluarga terutama anak - anak , sehingga ketika akan menonton video hanya bisa dari media server yang disediakan. Setelah pengaturan tersebut dilakukan maka ketika user yang terhubung ke jaringan server secara otomatis tidak akan bisa mengakses youtube.

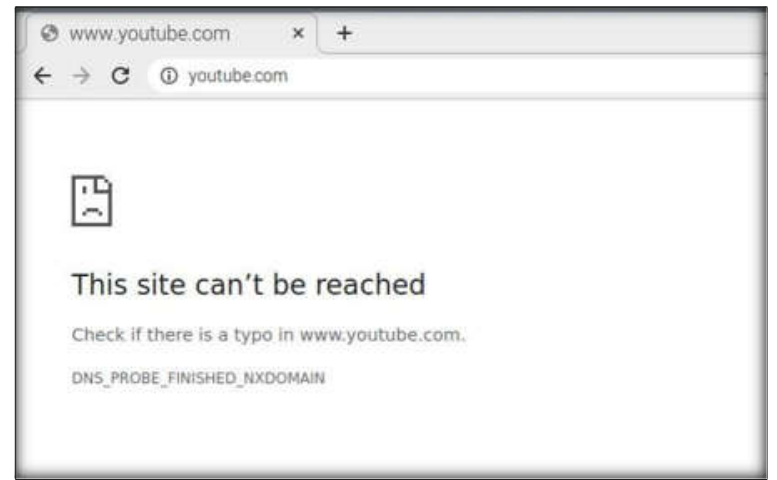

Gambar 9. Pemblokiran Youtube menggunakan AdguardHome

Pengujian selanjutnya, dilakukan dengan melihat log atau aktivitas setiap pengguna jaringan server yang digunakan. Dalam AdguardHome, menyediakan fitur untuk melihat setiap aktivitas interaksi atau transaksi penggunaan internet setiap user yang terhubung.

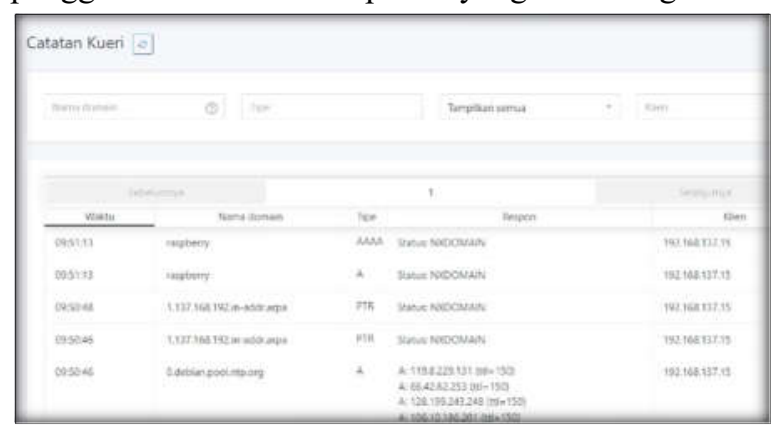

Gambar 10. Tampilan Aktivitas User

Terakhir, pengujian Adguardhome dilakukan terhadap kemampuan terhadap memblok iklan dari situs - situs yang diakses, dalam pengujian ini digunakan situs adblocker test (adblock-tester.com) dari hasil pengujian ini didapatkan nilai 65 dari 100 poin pemblokiran iklan pada situs ini.

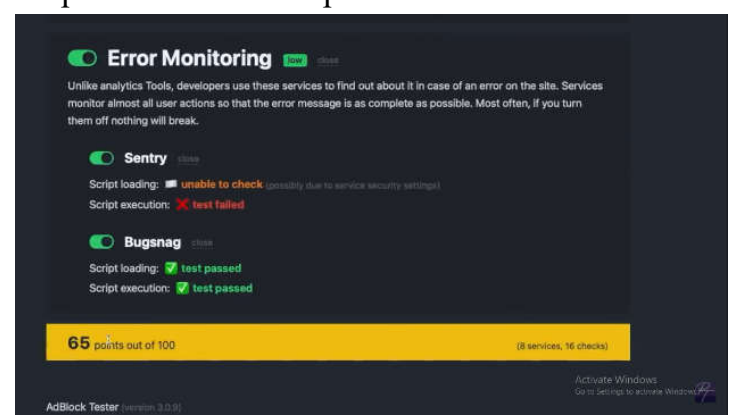

Gambar 11. Pengujian Adblock Tester 
Fitur lainnya dari adguardhome ini masih banyak dan bisa digunakan sesuai dengan keinginan user.

\subsection{Pengujian Plex Media Server}

Pada pengujian plex media server dilakukan beberapa tahapan. Langkah pertama menggunakan perangkat computer user dengan mengakses ipserver:32400(port):web (url yang disediakan plex media) pada web browser. Pada penelitian ini diakses url berikut : http://192.168.137.5:32400/web.

\section{PLEX}

Server Setup

Name

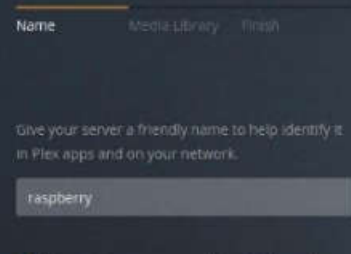

Gambar 12. Dashboard Plex Media Pertama kali Akses

Pada saat pertama kali akses, user akan diminta untuk mengatur nama dari server plex medianya dan akan diarahkan pada menu media.

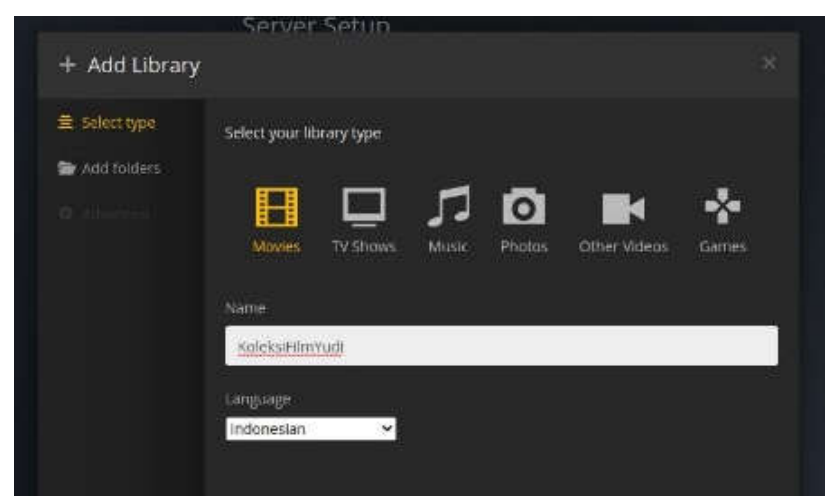

Gambar 13. Menu Library Plex Media

Pada menu Library, pengelola diminta membuat direktori untuk koleksi khusus yang akan ditampilkan pada menu user selanjutnya. Library atau directory tersebut akan muncul bersama dengan layanan Live tv, podcast dan layanan lainnya.

Selanjutnya user akan disarankan untuk mendapatkan atau mengunduh aplikasi berbasis android agar plexmedia bisa diakses dan digunakan menggunakan smartphone.

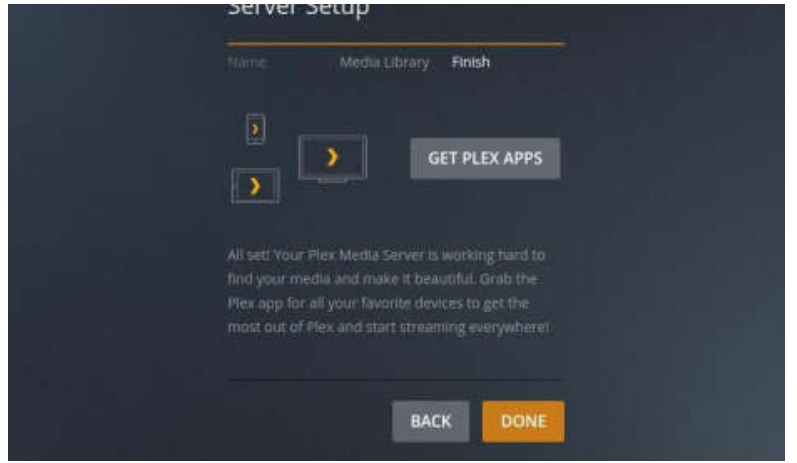

Gambar 14. Sugestion Get Plex Apps

Terakhir dalam Konfigurasi ini, akan diarahkan menuju dashboard user yang mengakses secara langsung. Perlu dicatat bahwa setup atau konfigurasi ini akan muncul ketika pertama kali diakses, jika sudah dikonfigurasi maka dashboard akan beralih menjadi seperti pada gambar 15 .

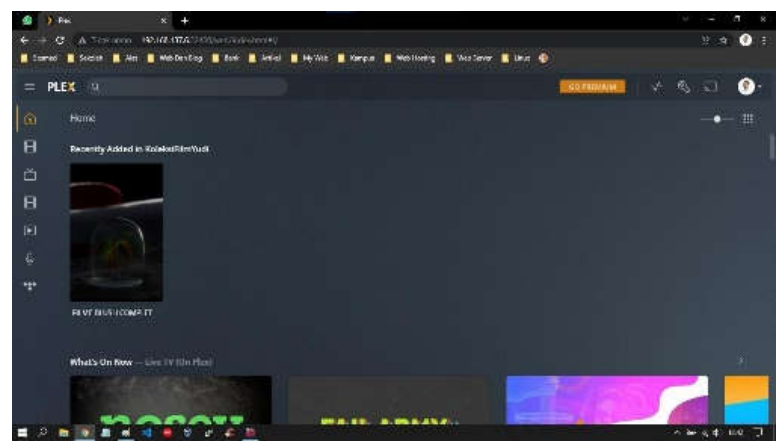

Gambar 15. Dashboard Plex Media setelah selesai Konfigurasi

Dalam penelitian ini, uji coba dilakukan dengan menambahkan 1 list daftar putar berupa video agar bisa diakses oleh user pada menu dashboard.

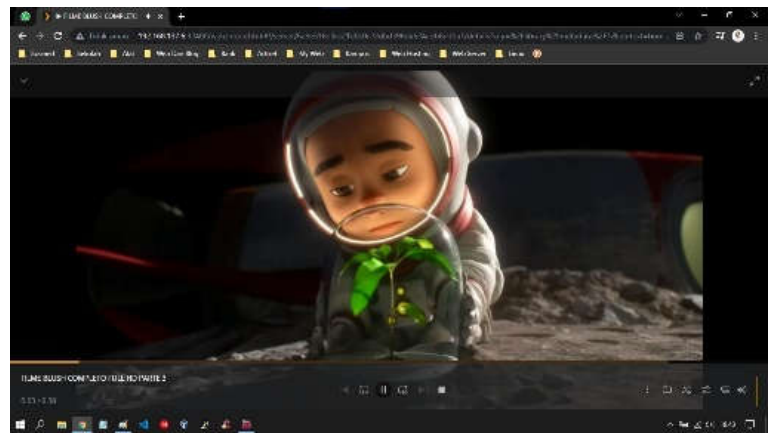

Gambar 16. Proses Pemutaran video Menggunakan Plex Media

Dalam proses pemutaran video menggunakan user computer, video berjalan dengan baik tanpa ada patah - patah dikarenakan mengakses secara langsung keserver. Pengujian lainnya dilakukan dengan 
menggunakan Smartphone android dengan aplikasi yang telah didapatkan dari Plex Media server pada saat konfigurasi sebelumnya.
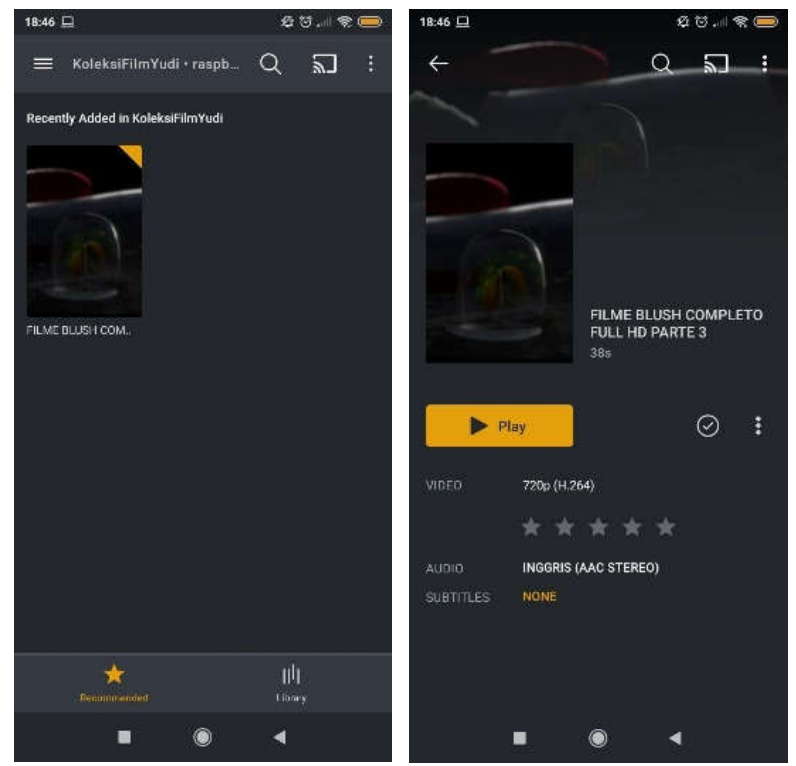

Gambar 17. Proses Pengujian menggunakan Aplikasi Smartphone

Dalam pengujiannya, Smartphone terlebih dahulu dikoneksikan kepada jaringan yang terhubung ke server, selanjutnya dilakukan installasi aplikasi dan ketika dibuka secara otomatis akan menampilkan apa yang disediakan oleh server yang digunakan.

\subsection{Pembahasan}

Dengan hasil dari pengujian dan implementasi, Raspberry pi dapat digunakan sebagai home server, atau lebih tepatnya Home Teater yang mana dapat menjaga akses keluarga dalam penggunaan internet, bisa digunakan untuk penghematan data internet karena flex media server dapat menyimpan film, musik dan media lainnya serta dapat diakses secara offline.

Kekurangan literasi digital keluarga juga bisa diatasi dengan filtering situs, pemblokiran iklan yang berbahaya dan monitoring akses internet untuk menjaga user agar tidak mengakses hal - hal yang tidak diinginkan.

\section{KESIMPULAN}

Dari hasil penelitian yang dilaksanakan, layanan yang dapat dipasang Raspberry pi khususnya Plex Media dan AdguardHome bisa digunakan untuk family protection. Mencegah akses berbahaya, monitoring pengguna berdasarkan sistus yang diakses dan memblokir iklan iklan yang menggangu atau membahayakan user. Selain itu fitur blok situs juga bisa digunakan untuk membatasi user khususnya keluarga dari pembatasan konten sesuai usia atau berdasarkan kepentingan lainnya.
Plex media sever sangat mumpuni digunakan untuk Home Teater / Home Server, bisa menjadi pengganti youtube anak dan konten yang disediakan bisa diatur oleh orang tua atau keluarga. Dengan adanya plex ini juga bisa menghemat dari sisi data internet karena bisa diakses secara offline.

Pengembangan kedepan dari penelitian ini adalah penambahan fitur NAS (Network Attached Storage) yang diperlukan untuk penyimpanan data media pada server karena Raspberry pi hanya mengandalkan penympanan SD Card.

\section{DAFTAR PUSTAKA}

[1] M. Salehudin, "TIDAK DIPAKE TDK COCOKLiterasi Digital Media Sosial Youtube Anak Usia Dini," J. Ilm. Potensia, vol. 5, no. 2, pp. 106-115, 2020.

[2] D. Keluarga, D. I. Tk, N. Pembina, and K. Lut, "(Print ISSN 2528-1402, Online ISSN 25495593)," vol. 5, no. 1, pp. 101-109, 2021.

[3] F. Hidayanto and M. Zidni Ilmi, "Pentingnya internet sehat," J. Inov. dan Kewirausahaan, vol. 4, no. 1, pp. 21-24, 2015.

[4] A. Shrivastava and J. Gadge, Home server and nas using raspberry PI. 2017.

[5] A. P. Jadhav and V. B. Malode, "Raspberry Pi based offline media server," Proc. 3rd Int. Conf. Comput. Methodol. Commun. ICCMC 2019, no. Iccmc, pp. 531-533, 2019, doi: 10.1109/ICCMC.2019.8819718.

[6] B. P. Yudo, U. Lestari, and A. Hamzah, "Jurnal JARKOM Vol . 2 No . 2 Desember 2014 MEMBANGUN MEDIA SERVER DENGAN MENGGUNAKAN RASPBERRY Pi Jurnal JARKOM Vol . 2 No . 2 Desember 2014," vol. 2, no. 2, pp. 12-21, 2014.

[7] D. Prihatmoko, "Pemanfaatan Raspberry Pi Sebagai Server Web Untuk Penjadwalan Kontrol Lampu Jarak Jauh," J. Infotel, vol. 9, no. $1, \quad$ p. $84, \quad 2017$, doi: 10.20895/infotel.v9i1.159.

[8] T. A. Mulyanto, M. Habiby, K. Kusnadi, and R. Adam, "Home Automation System Dengan Menggunakan Raspberry Pi 4," J. Digit, vol. 11, no. 1, p. 60, 2021, doi: 10.51920/jd.v11i1.180.

[9] B. Purnama, "Arsitektur teknologi webserver berbasis mini pc dengan raspberry pi," Akademika, vol. 9, no. August, pp. 281-285, 2016.

[10] F. Zuli and A. Irawan, "Implementasi Sistem Plex Media Server Berbasis Wireless Local Area Network," J. Satya Inform., pp. 39-49, 2017, [Online]. Available: https://teknik.usni.ac.id/jurnal/faizal.pdf.

[11] S. Nasional, T. Elektro, S. Informasi, and T. Informatika, "Seminar Nasional Teknik Elektro, Sistem Informasi, dan Teknik Informatika," no. 1, pp. 19-24, 2021.

Rudi Hermawan - 52 
[12] L. Ngah, A. Shakawi, and A. Sanusi, "Development of Rasberry Pi 3 Content Filtering and Ads Blocker," vol. 2, no. 1, pp. 82-91, 2021.

\section{BIODATA PENULIS}

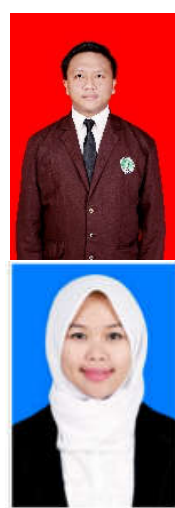

Rudi Hermawan, ST., MOS.

Alumni Program Studi Teknik Informatika, \& Staff IT STT YBSI Tasikmalaya dengan research interest Internet Of Things, Networking dan Artificial Inttelegence.

Siti Maesaroh, ST., M.Kom.

Dosen Kampus STT YBSI Prodi Teknik Informatika, Aktif juga sebagai Asesor Skema Network Administrator LSP Informatika.

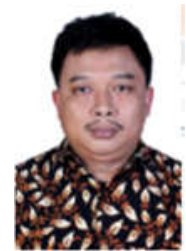

Dewanto Rosian Adhy, MT.

Dosen Kampus STT YBSI Tasikmalaya Prodi Teknik Informatika. Aktif dalam Asosiasi Perguruan Tinggi Informatika Ilmu dan Komputer (Aptikom)

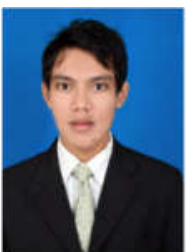

Jujun Juharsa, M.Kom.

Dosen STT YBSI Tasikmalaya Prodi Teknik Informatika. Scope Interest dibidang Sistem Informasi, Basis data dan Software Development

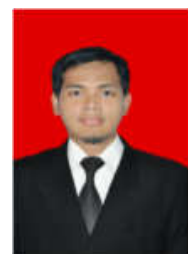

Ari Patriana, MT.

Dosen STT YBSI Tasikmalaya Prodi Teknik Informatika Sekaligus Praktisi IT dalam hal System Analis, Programming dan Software Development. 